\title{
Mireille Naturel, Proust et Flaubert. Un secret d'écriture
}

Geneviève Henrot Sostero

\section{(2) OpenEdition}

1 Journals

\section{Edizione digitale}

URL: http://journals.openedition.org/studifrancesi/8353

DOI: $10.4000 /$ studifrancesi.8353

ISSN: 2421-5856

\section{Editore}

Rosenberg \& Sellier

\section{Edizione cartacea}

Data di pubblicazione: 1 mai 2009

Paginazione: 204-205

ISSN: 0039-2944

\section{Notizia bibliografica digitale}

Geneviève Henrot Sostero, «Mireille Naturel, Proust et Flaubert. Un secret d'écriture», Studi Francesi

[Online], 157 (LIII | I) | 2009, online dal 30 novembre 2015, consultato il 13 janvier 2021. URL: http:// journals.openedition.org/studifrancesi/8353 ; DOI: https://doi.org/10.4000/studifrancesi.8353

Questo documento è stato generato automaticamente il 13 janvier 2021.

\section{(c) (†) $\ominus$}

Studi Francesi è distribuita con Licenza Creative Commons Attribuzione - Non commerciale - Non opere derivate 4.0 Internazionale. 


\title{
Mireille Naturel, Proust et Flaubert. Un secret d'écriture
}

\author{
Geneviève Henrot Sostero
}

\section{NOTIZIA}

MIREILLE NATUREL, Proust et Flaubert. Un secret d'écriture, édition nouvelle et augmentée, Amsterdam-New York, Rodopi, 2007 («Faux Titre», 173), pp. 485.

1 I rapporti tra Proust e Flaubert presentano al critico diversi tipi di difficoltà. Ogni grande modello letterario subisce in Proust un destino simile ad una fagocitazione intellettuale: intense letture, saggi critici, imitazioni stilistiche tramite semplice copia o citazione, elaborate in pastiche o in mise en abyme parodica, appunti marginali nei manoscritti, espressioni predilette o motivi riconoscibili sono via via destinati ad essere abbandonati, o addirittura cancellati, per lasciare posto, invece, ad una traccia sotterranea molto più subdola e di delicata diagnosi.

2 L'A., specialista del confronto tra i due scrittori, ripropone un'edizione aggiornata ed ampliata di un precedente Proust et Flaubert (Amsterdam-Atlanta, Rodopi, 1999), il cui obiettivo non è tanto di paragonare i due, o di soppesare l'influenza del secondo sul primo, bensì di capire come e quanto il secondo abbia consentito al primo di trovare la propria via, tra ammirazione e distanza, identificazione e profanazione. Un apporto fondamentale proviene dalla corrispondenza di Proust da una parte, e dall'altra, dal ricchissimo fondo dei suoi manoscritti.

Strutturato in cinque parti, questo saggio ponderoso e rigorosamente documentato unisce percorso cronologico e tagli tematici: «Proust lecteur et critique de Flaubert» (pp. 17-108) ripercorre gli esordi della creazione nelle sue tracce testuali e contestuali (carteggi, appunti di letture, pastiches). La seconda parte confronta a coppie i personaggi femminili di Proust e Flaubert («Les "femmes" du Narrateur», pp. 109-179). La terza parte focalizza alcuni motivi di scrittura più puntuali, quali i "papaveri”, il "sole-ostensorio", la "vetrata di Combray", il "personaggio-uccello" («Motifs 
poétiques», pp. 181-258), per rendere più sensibili le risonanze flaubertiane che essi lasciano echeggiare. La quarta parte («Du social et de l'esthétique», pp. 259-311) si sofferma sul quadro sociale tracciato negli ambiti mondani marittimi e artistici. La quinta e ultima parte («La création littéraire», pp. 313-409) riallaccia il filone cronologico per scandire la presenza di Flaubert nell'immaginario creativo di Proust tra misteriosa attrazione, cancellazione, risurrezione e sublimazione. Tre appendici dettagliano la presenza di Flaubert nel Carnet de 1908 e nella Correspondance e propongono un brano di Flaubert (Novembre), molto vicino a certi accenti proustiani in Albertine. Utilissimi i sette indici finali: opere di Proust e opere di Flaubert, nomi di artisti e critici, nomi di luoghi e personaggi, oggetti e motivi, indice tematico e indice degli avantesti. 